\title{
Article \\ Changing Cross-Reactivity for Different Immunoassays Using the Same Antibodies: Theoretical Description and Experimental Confirmation
}

\author{
Dmitriy V. Sotnikov ${ }^{1, *}$, Anatoly V. Zherdev ${ }^{1}\left(\mathbb{D}\right.$, Elena A. Zvereva ${ }^{1}$, Sergei A. Eremin ${ }^{2}(\mathbb{D}$ and Boris B. Dzantiev $1, * \mathbb{C}$ \\ 1 A.N. Bach Institute of Biochemistry, Research Center of Biotechnology of the Russian Academy of Sciences, \\ Moscow 119071, Russia; zherdev@inbi.ras.ru (A.V.Z.); zverevaea@yandex.ru (E.A.Z.) \\ 2 Department of Chemical Enzymology, Chemical Faculty, M.V. Lomonosov Moscow State University, \\ Moscow 119234, Russia; eremin_sergei@hotmail.com \\ * Correspondence: sotnikov-d-i@mail.ru (D.V.S.); dzantiev@inbi.ras.ru (B.B.D.)
}

check for updates

Citation: Sotnikov, D.V.; Zherdev, A.V.; Zvereva, E.A.; Eremin, S.A.;

\section{Dzantiev, B.B. Changing}

Cross-Reactivity for Different

Immunoassays Using the Same

Antibodies: Theoretical Description and Experimental Confirmation. Appl. Sci. 2021, 11, 6581. https://doi.org/ 10.3390/app11146581

Academic Editors: Marina Nisnevitch and Galina Gayda

Received: 7 May 2021

Accepted: 13 July 2021

Published: 17 July 2021

Publisher's Note: MDPI stays neutral with regard to jurisdictional claims in published maps and institutional affiliations.

Copyright: (c) 2021 by the authors. Licensee MDPI, Basel, Switzerland. This article is an open access article distributed under the terms and conditions of the Creative Commons Attribution (CC BY) license (https:// creativecommons.org/licenses/by/ $4.0 /)$.

\begin{abstract}
Many applications of immunoassays involve the possible presence of structurally similar compounds that bind with antibodies, but with different affinities. In this regard, an important characteristic of an immunoassay is its cross-reactivity: the possibility of detecting various compounds in comparison with a certain standard. Based on cross-reactivity, analytical systems are assessed as either high-selective (responding strictly to a specific compound) or low-selective (responding to a number of similar compounds). The present study demonstrates that cross-reactivity is not an intrinsic characteristic of antibodies but can vary for different formats of competitive immunoassays using the same antibodies. Assays with sensitive detection of markers and, accordingly, implementation at low concentrations of antibodies and modified (competing) antigens are characterized by lower cross-reactivities and are, thus, more specific than assays requiring high concentrations of markers and interacting reagents. This effect was confirmed by both mathematical modeling and experimental comparison of an enzyme immunoassay and a fluorescence polarization immunoassay of sulfonamides and fluoroquinolones. Thus, shifting to lower concentrations of reagents decreases cross-reactivities by up to five-fold. Moreover, the cross-reactivities are changed even in the same assay format by varying the ratio of immunoreactants' concentrations and shifting from the kinetic or equilibrium mode of the antigen-antibody reaction. The described patterns demonstrate the possibility of modulating immunodetection selectivity without searching for new binding reactants.
\end{abstract}

Keywords: immunodetection; specificity of antibodies; cross-reactivity; mathematical modeling; competitive interactions; enzyme immunoassay; fluorescence polarization immunoassay; sulfonamides; fluoroquinolones

\section{Introduction}

The possibility of obtaining antibodies that can bind very different compounds has led to the intense development of immunoanalytical systems. In modern practice, various forms of immunoassay are successfully used in medical diagnostics, quality and safety control of consumer products, environmental monitoring, etc. [1-4]. The advantages of immunoanalytical methods include simple sample preparation and assay implementation, highly productive testing, and the absence of the need for sophisticated equipment and highly trained operators. In many cases, immunoassays are adapted for autonomous realization directly at sampling locations, i.e., point-of-care (POC) diagnostics [5-7]. Depending on the tasks to be solved and the available equipment, various analysis formats can be realized with different labels and instrumentation. These formats of immunoassays include enzyme immunoassay, immunoagglutination, lateral-flow and through-flow membrane immunoassays, systems that detect the intensity or polarization of fluorescence, electrochemical immunosensors, etc. [8,9]. 
Despite the ability of antibodies to detect target antigens in complex matrices with high recovery, immunoassays have significant limitations. First of all, due to the structure of an antibody's binding site and its mechanisms of antigen binding, it can potentially reveal the presence of a number of chemically similar substances rather than a single compound. Occasionally, information on the total content of all such compounds is of practical interest because of their similar biological actions. In other cases, it is necessary to identify a strictly defined substance or a minimum number of its derivatives with high functional activity against the background of other structural analogs not possessing this activity. However, the result of an immunoassay is the total number of formed and detected immune complexes, without data on which antigen variants were involved in their formation $[8,10]$. Therefore, for analysis, a decision on the required specificity is made in each case based on the specific task. Reactants can be searched for either high-selective (responding strictly to a specific compound) or low-selective (responding to a number of similar compounds) immunoassays.

To estimate the detection of chemically similar substances by immunotechniques, cross-reactivity (CR) is the most commonly used parameter [11]. Considering the detection of a main analyte and a cross-reactant, the ratio of their concentrations causing the same analytical signal is considered a measure of cross-reactivity. In the case of competitive immunoassay formats (which are typically used for the detection of low molecular weight monovalent antigens), a generally accepted recommendation for maximal measurement accuracy is to calculate the cross-reactivity as the ratio of the concentrations causing a $50 \%$ decrease in the detected signal $[8,12]$ :

\section{Cross-reactivity $(\mathrm{CR})=\mathrm{IC} 50$ (target analyte) $/ \mathrm{IC50}$ (tested cross-reactant) $\times 100 \%$}

The search for an assay with the necessary parameters of cross-reactivity may be realized as a simple screening of different available antibodies (comparison of reagents from different manufacturers, transition from monoclonal to polyclonal drugs or vice versa, the formation of mixtures of antibodies [13]), but when using the same immunogen, the variability of antibody selectivity is limited. Moreover, such screening requires access to a large number of preparations and is limited by financial factors when working with commercially prepared antibodies.

A number of approaches have been presented in the literature to date that allow for a targeted influence on the selectivity of immunoassays. The most common is to design an antigenic preparation for the best presentation of either unique or common epitope(s) for antibody generation [14-18]. In a number of cases, the results of such a design have been successful and made it possible to obtain antibodies with the required spectrum of selectivity. However, such actions are not always possible. They are often aggravated by the low immunogenicity or non-uniqueness of the selected structures and, moreover, require complex preliminary chemical synthetic work. An alternative approach to competitive immunoassays is to use different antigen derivatives in immunization and analysis [19-28]. This so-called "heterologous" immunoassay ensures that not all antibodies produced are involved in the competitive analytical interactions, and the spectrum of selectivity is thereby narrowed in comparison with the traditional "homologous" assay. For immunoassays based on the use of monoclonal antibodies, the "heterologous" approach is also applicable, and the changed affinity of antibodies to conjugated hapten causes shifts in the ratio between free and conjugated haptens-these shifts depend on the properties of free haptens. However, the degree of the differences varies in an unpredictable way, and additionally, the use of different antigen derivatives implies additional chemical synthetic work.

Despite the development of theoretical tools for predicting most immunogenic structures (such as 3D modeling of immune complexes and quantitative structure-activity relationship (QSAR) analysis [29-32]), the established regularities often only relate to certain classes of chemical compounds and cannot be transferred to other classes without additional theoretical analysis and experimental verification. Another way to change selectivity is mutational modification, including targeted genetic design of the antigen-binding 
sites of antibodies $[33,34]$. However, these works require very significant additional time and resources and are currently limited to a short list of successful developments.

Other special solutions for controlling the selectivity of immunodetection have also been described. These include additional chemical modification of antigens to reduce the contribution of variable structures to the affinity of immune recognition, the immunogenic use of specially designed compounds recreating universal structures for target chemical classes, and the treatment of samples to convert various forms of antigen into similar conformations $[35,36]$. However, these decisions are based on the chemical characteristics of specific groups of compounds and cannot be applied to all other groups. It was noted [8] that the impact of low- and high-affine subfractions of polyclonal antibodies on the formation of the detected immune complexes differed with the change in analyte content. Based on this reason, the addition of a small quantity of cross-reacting analyte was successfully used to block undesirable high-affine subfractions of antibodies [37]. However, blocking or removing unwanted cross-reactants also implies the use of additional reagents that selectively bind strictly defined types of antigenic molecules, which again depends on the individual properties of the compounds and is far from always possible. Among other tools influencing the cross-reactivity of an assay, the composition of the reaction medium should be indicated. The influence of $\mathrm{pH}$ or other assay conditions on its selectivity was indicated [38-41]. For example, varied concentrations of urea can radically change the cross-reactivities of different assay formats [42]. However, such phenomena are also based on the individual characteristics of antigens; the described effects are poorly predictable and cannot be transferred to other antigens. Occasionally, alternate assay formats are proposed with other schemes of reagent interaction-for example, non-competitive schemes for low molecular weight antigens or simple changes in the order of addition of reagents [43,44]. However, examples of their successful implementation are limited, and such a replacement can lead to deterioration in sensitivity.

Given the demand for variable selectivity of immunodetection, the possibilities available in cases of limited antibody resources and means of chemical modification of antigens are of interest. The present article shows that cross-reactivity is not a fixed parameter determined exclusively by immunoreagents but is an integral parameter sensitive to the conditions of the analysis, as will be shown below. A simple resource for influencing this parameter is the implementation of different assay formats, in which, due to the use of different markers of immune complexes and the means of their registration, interactions are carried out at different concentrations of immunoreagents. This shift in concentrations has different effects on the detection of antigens differing in affinity to antibodies. Moreover, changed concentrations of immunoreactants and varied immune interaction times (approaching kinetic or equilibrium conditions) influence cross-reactivities even in the same assay format. As a result, cross-reactivities change and the assay shifts either to a more molecule-specific or to a more class-specific one. Although changes in the assay formats, labels used, and reagent ratios are common actions in assay development, their use is judged mainly in terms of lowering the detection limit; then, the accompanying changes in cross-reactivity are commented on in a few works [45-47].

In the present study, mathematical modeling of the expected effects of the approach described above and experimental verification were carried out for two immunoassay formats. The mathematical model uses previously proposed descriptions of competitive immunoassays [48-50] and focuses on unexplored regularities in antigens differing in affinity without consideration of non-target interferences [51]. The obtained theoretical solutions show the versatility of the idea and the promise of its application for different compounds. Experimental verification demonstrates the adequacy of the theoretical assumptions and conclusions. The experiments were carried out on systems of immunodetection of sulfonamides (SAs) and fluoroquinolones, which are widely used antibiotics that are represented by dozens of structurally similar compounds and, due to their toxic effects, have official requirements for their control as contaminants of food products, such as meat, milk and dairy products, and honey [52,53]. Two immunoassay formats were consid- 
ered: fluorescence polarization immunoassay (FPIA) and enzyme-linked immunosorbent assay (ELISA).

\section{Materials and Methods}

\subsection{Mathematical Modeling}

The descriptions of competitive assay schemes were considered in the form of algebraic solutions for systems of three chemically acting reagents: antigen in a sample $(\mathrm{Ag})$, modified antigen competitor $\left(\mathrm{Ag}^{*}\right)$, and antibodies $(\mathrm{Ab})$. The calculations in Section 3.1 use previously proposed models of equilibrium competitive immunoassays [48-50]. Subsequent modeling of $C R$ variations under different conditions of immunoassays was implemented by algebraic solutions specifically for this study. The results of the subsequent calculations of the concentration curves for the chosen model parameters of immune interactions were presented by dependencies built using Origin software (OriginLab Corp., Northampton, MA, USA).

\subsection{Obtaining Antibodies}

Polyclonal antibodies against SAs were produced as previously described [54]. Briefly, male brush rabbits at the age of 3-5 months were immunized every 2 weeks with the conjugate of bovine serum albumin and the corresponding SA $(0.5-1.0 \mathrm{mg} / \mathrm{mL})$ mixed at equal volume with complete Freund's adjuvant for the first immunization and with incomplete Freund's adjuvant for subsequent immunizations.

Bleeds were taken from the marginal ear vein using vacuum tubes with gel and a coagulation activator. The serum was separated by centrifugation and then treated by a three-stage bedding method with ammonium sulfate at $+4{ }^{\circ} \mathrm{C}$. The resulting solution of immunoglobulin $\mathrm{G}(\mathrm{IgG})$ of electrophoretically confirmed homogeneity was mixed with an equal volume of glycerol and stored at $-20^{\circ} \mathrm{C}$.

\subsection{Obtaining Reactants for Immunoassays}

SAs were conjugated with amine-containing fluorescein derivatives for use as labeled competitors in FPIA by the carbodiimide technique and purified by thin-layer chromatography, as described in $[54,55]$. Conjugates of SAs with bovine serum albumin for immunizations or ovalbumin for competitive immune interactions in ELISA were obtained using the carbodiimide technique with the separation of non-interacting low molecular weight compounds by dialysis. Peroxidase-modified anti-species antibodies were purchased from Imtek (Moscow, Russia) and used in ELISA.

\subsection{FPIA of Sulfonamides (SAs)}

The FPIA protocol is based on [54]. The degree of fluorescence polarization caused by plane-polarized excitation light was registered using a TDx analyzer (Abbott, Chicago, IL, USA). In special cuvettes, $300 \mu \mathrm{L}$ of diluted SA-(fluorescein derivative) conjugate, $50 \mu \mathrm{L}$ of tested dilutions of SAs, and $50 \mu \mathrm{L}$ of diluted antisera $(50 \mathrm{mM}$ borate buffer, $\mathrm{pH}$ 9.6, used for all dilutions) were mixed and incubated for $5 \mathrm{~min}$ at room temperature before measuring polarization fluorescence values at an excitation wavelength of $485 \mathrm{~nm}$ and an emission wavelength of $535 \mathrm{~nm}$. The chosen optimal assay conditions had an antibody concentration of $0.2 \mathrm{nM}$ and an SA-(fluorescein derivative) conjugate concentration of $0.16 \mathrm{nM}$.

\subsection{ELISA of $S A$}

The ELISA protocol is based on [54]. SA conjugates with ovalbumin were immobilized in microplate wells, and then, $50 \mu \mathrm{L}$ of SA-containing samples and $50 \mu \mathrm{L}$ of antibody dilutions (in $50 \mathrm{mM}$ phosphate buffer, $\mathrm{pH} 7.4$, with $0.1 \mathrm{M} \mathrm{NaCl}$ and $0.05 \%$ Tween-20) were incubated for $1 \mathrm{~h}$ at $37^{\circ} \mathrm{C}$. After microplate washing, the formed immune complexes were labeled by additional 1-h incubation with peroxidase-modified anti-species antibodies, and peroxidase activity was registered using tetramethylbenzidine $+\mathrm{H}_{2} \mathrm{O}_{2}$ substrate and $2 \mathrm{M}$ $\mathrm{H}_{2} \mathrm{SO}_{4}$ as a stop reactant. Photometric measurements were taken using a microplate reader 
at $450 \mathrm{~nm}$. The chosen optimal assay conditions had an approximate effective concentration of immobilized SA at the competitive stage of $76 \mathrm{nM}$ and a specific antibody concentration of $0.3 \mathrm{nM}$.

\subsection{ELISA of Clinafloxacin (CLI)}

A CLI-OVA conjugate $(100 \mathrm{~mL}, 0.5 \mu \mathrm{g} / \mathrm{mL})$ in $50 \mathrm{mM}$ potassium phosphate buffer, $\mathrm{pH} 7.4$, containing $0.1 \mathrm{M} \mathrm{NaCl}$ (PBS) was adsorbed in microplate wells at $4{ }^{\circ} \mathrm{C}$ overnight. The microplate was washed four times with PBS containing 0.05\% Triton X-100 (PBST). After that, $50 \mu \mathrm{L}$ of CLI, MOX, or ENR solution in PBST (concentration from $10 \mu \mathrm{g} / \mathrm{mL}$ to $0.01 \mathrm{ng} / \mathrm{mL}$ ) was added to the wells, followed by the addition of $50 \mu \mathrm{L}$ of an antibody against CLI (in a dilution of 1:20,000). The microplate was incubated for $7 \mathrm{~min}$ or $1 \mathrm{~h}$ at $37^{\circ} \mathrm{C}$ and washed four times with PBST. After this, $100 \mu \mathrm{L}$ of the peroxidase-labeled anti-rabbit immunoglobulins (1:5000 dilution of commercial preparation in PBST) was added to the wells, the microplate was incubated for $1 \mathrm{~h}$ at $37^{\circ} \mathrm{C}$ and washed four times with PBST, and the activity of the peroxidase label was detected. For the detection, $100 \mu \mathrm{L}$ of TMB $+\mathrm{H}_{2} \mathrm{O}_{2}$ substrate solution (Immunotech, Moscow, Russia) was added to all wells, incubated at room temperature, and the reaction was stopped by addition of $1 \mathrm{M} \mathrm{H}_{2} \mathrm{SO}_{4}$ ( $50 \mu \mathrm{L}$ per well). The optical density of the reaction product was measured at $450 \mathrm{~nm}$ using a Zenyth 3100 microplate photometer (Anthos Labtec Instruments, Salzburg, Austria).

\subsection{Experimental Data Processing and Cross-Reactivity Calculation}

The concentration dependences of the recorded optical signals for all types of analyses were built based on the results of testing solutions of SAs. The obtained curves reflecting competitive interactions were approximated by four-parameter sigmoidal fittings: $\mathrm{Y}=(\mathrm{A}$ $-\mathrm{D}) /\left(1+(\mathrm{x} / \mathrm{C})^{\mathrm{B}}\right)+\mathrm{D}$. $\mathrm{C}$-values of fit represent the point of inflection of the curve (i.e., the point on the S-shaped curve halfway between $\mathrm{A}$ and $\mathrm{D}$ ). Therefore, the $\mathrm{C}$-values were used as the $\mathrm{IC}_{50}$ (i.e., the analyte concentrations causing $50 \%$ inhibition of the detected label's binding) to calculate cross-reactivities as described in Section 1.

\section{Results and Discussions}

\subsection{Model of Competitive Immunoassay}

In the course of a competitive immunoassay with a modified antigen, three compounds interact simultaneously: the antigen-binding sites of antibodies $(\mathrm{Ab})$, an unlabeled antigen in the tested sample $(\mathrm{Ag})$, and a modified competing antigen $\left(\mathrm{Ag}^{*}\right)$. This leads to the formation of two types of complexes having the compositions $\mathrm{AbAg}$ and $\mathrm{AbAg}$. The registered signal reflects the content of the second complex. Therefore, the calibration dependence of the assay accords with the dependence of the concentration of [ $\left.\mathrm{AbAg}^{*}\right]$ on the initial concentration of the added unlabeled antigen $[\mathrm{Ag}]_{0}$. (The subscript " 0 " here and below indicates the starting time $t=0$.) Various formats of competitive immunoassay differ only in specifications for the considered reactants while demonstrating the same calibration dependence. Thus, for ELISA, Ag* is an antigen immobilized on the solid phase, and the registered signals are determined by the formation of the $\mathrm{AbAg}^{*}$ complexes. The introduction of a detectable label directly during the competition (as in the considered FPIA) or at a subsequent stage (as in the experimentally studied variant of ELISA) affects the signal intensity, but not its concentration dependence.

Therefore, the following chemical processes should be considered when describing a competitive immunoassay, taking into account the notations introduced above:

$$
\begin{gathered}
A b+A g \leftrightarrow A b A g \\
A b+A g^{*} \leftrightarrow A b A g^{*}
\end{gathered}
$$


The rates of change in the concentrations of all reagents are described by a system of differential equations:

$$
\begin{gathered}
\frac{\partial[A b A g]}{\partial t}=\frac{-\partial[A g]}{\partial t}=\mathrm{k}_{\mathrm{a} 1}[A b][A g]-\mathrm{k}_{\mathrm{d} 1}[A b A g] \\
\frac{\partial\left[A b A g^{*}\right]}{\partial t}=\frac{-\partial\left[A g^{*}\right]}{\partial t}=\mathrm{k}_{\mathrm{a} 2}[A b]\left[A g^{*}\right]-\mathrm{k}_{\mathrm{d} 2}\left[A b A g^{*}\right] \\
\frac{\partial[A b]}{\partial t}=\frac{\partial\left[A g^{*}\right]}{\partial t}+\frac{\partial[A g]}{\partial t}
\end{gathered}
$$

where $\mathrm{k}_{\mathrm{ai}}$ and $\mathrm{k}_{\mathrm{di}}$ denote the kinetic constants of association and dissociation, respectively.

When carrying out the analysis in equilibrium mode (the rates of change in concentrations reach zero values), the system of differential Equations (3)-(5) turns into a system of algebraic equations:

$$
\begin{gathered}
\mathrm{k}_{\mathrm{a} 1}[A b][A g]-\mathrm{k}_{\mathrm{d} 1}[A b A g]=0 \\
\mathrm{k}_{\mathrm{a} 2}[A b]\left[A g^{*}\right]-\mathrm{k}_{\mathrm{d} 2}\left[A b A g^{*}\right]=0
\end{gathered}
$$

The concentrations of the reactants are also related by the equations of the mass conservation law:

$$
\begin{gathered}
{[A g]_{0}=[A g]+[A b A g]} \\
{\left[A g^{*}\right]_{0}=\left[A g^{*}\right]+\left[A b A g^{*}\right]} \\
{[A b]_{0}=[A b]+[A b A g]+\left[A b A g^{*}\right]}
\end{gathered}
$$

The equilibrium dissociation constants of the $A b A g$ and $A b A g^{*}$ complexes are denoted below as $\mathrm{K}_{\mathrm{d} 1}$ and $\mathrm{K}_{\mathrm{d} 2}$, respectively:

$$
\begin{aligned}
& \frac{[A b A g]}{[A g]}=\frac{\mathrm{k}_{\mathrm{a} 1}}{\mathrm{k}_{\mathrm{d} 1}}[A b]=\frac{[A b]}{\mathrm{K}_{\mathrm{d} 1}} \\
& \frac{\left[A b A g^{*}\right]}{\left[A g^{*}\right]}=\frac{\mathrm{k}_{\mathrm{a} 2}}{\mathrm{k}_{\mathrm{d} 2}}[A b]=\frac{[A b]}{\mathrm{K}_{\mathrm{d} 2}}
\end{aligned}
$$

The complex of Equations (8)-(12) completely describes the equilibrium competitive system and allows a cubic equation to be derived for the equilibrium concentrations of each of the components, as was demonstrated in [40-42]. For example, for the concentration of free antibodies, the cubic equation is as follows:

$$
[A b]^{3}+\mathrm{a}[A b]^{2}+\mathrm{b}[A b]+\mathrm{c}=0
$$

where $\mathrm{a}=\mathrm{K}_{\mathrm{d} 1}+\mathrm{K}_{\mathrm{d} 2}+[A g]_{0}+\left[A g^{*}\right]_{0}-[A b]_{0} ; \mathrm{b}=\mathrm{K}_{\mathrm{d} 2}\left([A g]_{0}-[A b]_{0}\right)+\mathrm{K}_{\mathrm{d} 1}\left(\left[A g^{*}\right]_{0}-[A b]_{0}\right)$ $+\mathrm{K}_{\mathrm{d} 2} \mathrm{~K}_{\mathrm{d} 1} ; \mathrm{c}=-\mathrm{K}_{\mathrm{d} 2} \mathrm{~K}_{\mathrm{d} 1}[A b]_{0}$.

A trigonometric transformation provides a solution for this equation:

$$
[A b]=-\frac{a}{3}+\frac{2}{3} \sqrt{\left(a^{2}-3 b\right)} \cos \frac{\theta}{3}
$$

where $\theta=\arccos \frac{-2 a^{3}+9 a b-27 c}{2 \sqrt{\left(a^{2}-3 b\right)^{3}}}$.

Using this solution, we can calculate the concentration of the detected complex $\left[A b A g^{*}\right]$ :

$$
\left[A b A g^{*}\right]=\frac{\left[A g^{*}\right]_{0}\left(2 \sqrt{\left(\mathrm{a}^{2}-3 \mathrm{~b}\right)} \cos \frac{\theta}{3}-\mathrm{a}\right)}{3 \mathrm{~K}_{\mathrm{d} 2}+\left(2 \sqrt{\left(\mathrm{a}^{2}-3 \mathrm{~b}\right)} \cos \frac{\theta}{3}-\mathrm{a}\right)}
$$

Equation (15) describes the calibration curve of the assay. Substituting various values of the initial concentrations and interaction parameters into this equation, one can study the influence of these factors on the position and amplitude of the calibration curve. This 
property makes it possible to use Equation (15) to estimate the $C R$ variation for structurally similar analytes tested under different conditions of competitive immunoassay.

\subsection{Influence of Reaction Parameters on the $I C_{50}$ Values}

Figure 1 shows the theoretical calibration curves with varying $K_{d 1}$ values for two initial concentrations of labeled antigen. Note that the position of the calibration curve and, accordingly, the $\mathrm{IC}_{50}$ value both depend on the binding constant and on the concentrations of the reagents used.

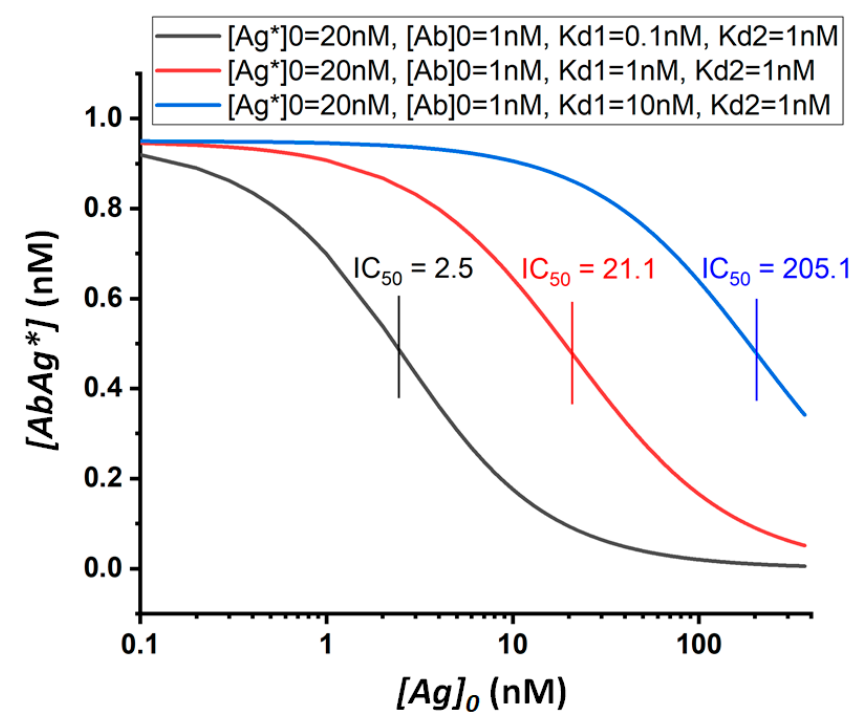

(a)

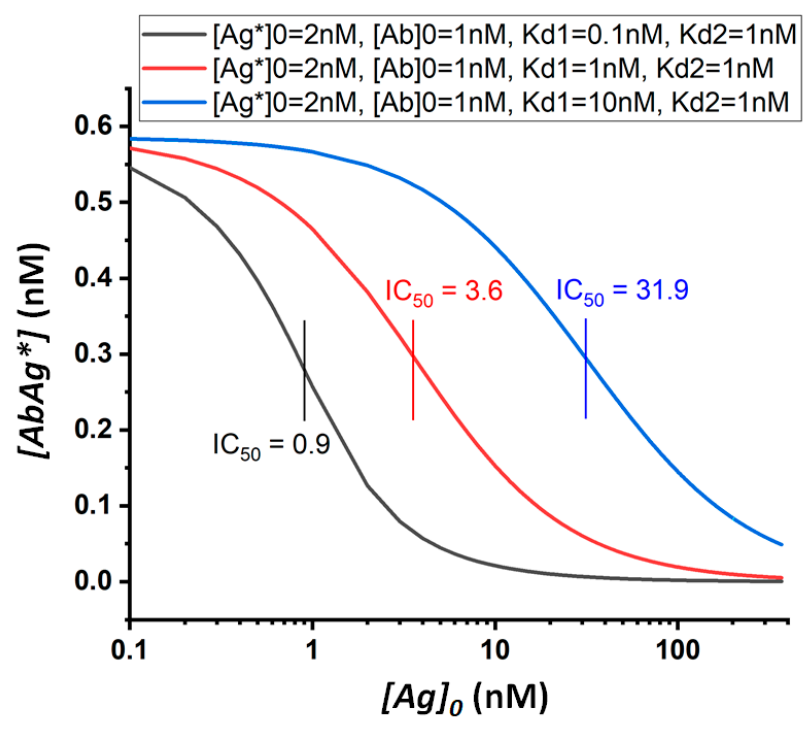

(b)

Figure 1. Theoretical calibration dependences of equilibrium competitive immunoassay at different values of the equilibrium dissociation constant of the antibody-unlabeled-antigen complex. The quantities inserted into Equation (15) are shown in the sidebars. (a) shows the variance of the constant $\mathrm{K}_{\mathrm{d} 1}$ from 0.1 to $10 \mathrm{nM}$ at $\left[A g^{*}\right]_{0}=20 \mathrm{nM}$; (b) shows the same variance of the $\mathrm{K}_{\mathrm{d} 1}$ constant at $\left[A g^{*}\right]_{0}=2 \mathrm{nM}$.

By varying several parameters of the assay simultaneously, it is possible to adjust the parameters of the calibration curve to achieve the desired signal intensity and $\mathrm{IC}_{50}$. Thus, Figure 2 demonstrates the combined effect of the initial concentrations of the labeled antigen and antibodies on the shape and position of the calibration curve. The signal intensity is determined by the smaller of the parameters $[A b]_{0}$ and $\left[\mathrm{Ag}^{*}\right]_{0}$. Both parameters affect the $\mathrm{IC}_{50}$ in three ways: (i) a decrease in the concentration of antibodies decreases the $\mathrm{IC}_{50}$; (ii) with an excess of antibodies, a decrease in $\left[\mathrm{Ag}^{*}\right]_{0}$ leads to a decrease in the amplitude of the signal change and an increase in the $\mathrm{IC}_{50}$; (iii) with a lack of antibodies, a decrease in $\left[\mathrm{Ag}^{*}\right]_{0}$ leads to a decrease in both the amplitude and $\mathrm{IC}_{50}$.

By reducing $[A b]_{0}$ and $\left[\mathrm{Ag}^{*}\right]_{0}$, a shift in $\mathrm{IC}_{50}$ towards lower values can be achieved, which potentially accords with a lower limit of detection. However, this process is accomplished by a decrease in detected signals, and thus, reliable measurements may become impossible. Thus, the low limit of detection reached depends on the minimum concentration of the label that can be detected in a given assay format. The effect of changes in the concentrations of the immunoreagents used in the analysis on the cross-reactivity values requires additional consideration, which is given below. 


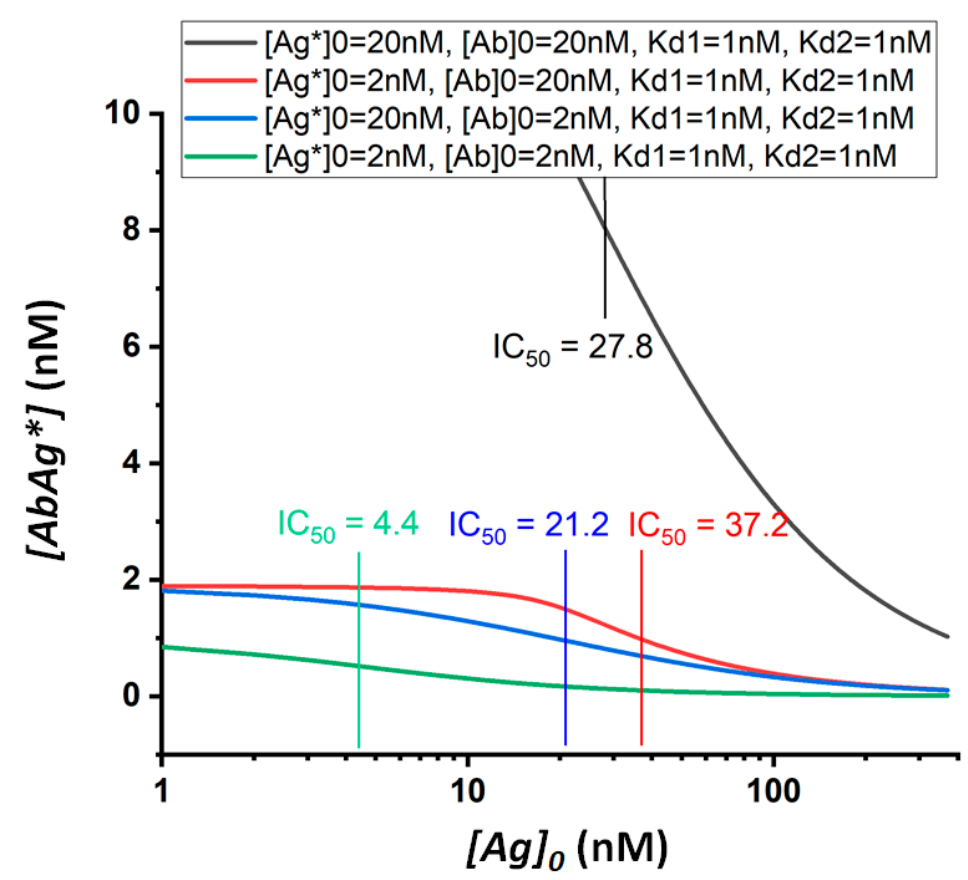

Figure 2. Theoretical calibration dependences of equilibrium competitive immunoassay at different values of the initial concentrations of the labeled antigen and antibodies.

\subsection{Theoretical Dependence of $C R$ on the Analysis Format}

When determining several structurally similar compounds under the same concentrations of analytical reagents, the cross-reactivity will be determined by the constants of the interactions of these compounds with antibodies. Figure 3 shows theoretical calibration curves for three model analytes (I, II, and III) with the equilibrium dissociation constants of their immune complexes equal to $0.1,1$, and $10 \mathrm{nM}$. The curves were calculated for three chosen concentrations of analytical reactants: assay (a), $[A b]_{0}=1 \mathrm{nM},\left[A g^{*}\right]_{0}=1 \mathrm{nM}$; assay (b), $[A b]_{0}=10 \mathrm{nM},\left[A g^{*}\right]_{0}=1 \mathrm{nM}$; and assay (c), $[A b]_{0}=10 \mathrm{nM},\left[A g^{*}\right]_{0}=10 \mathrm{nM}$.

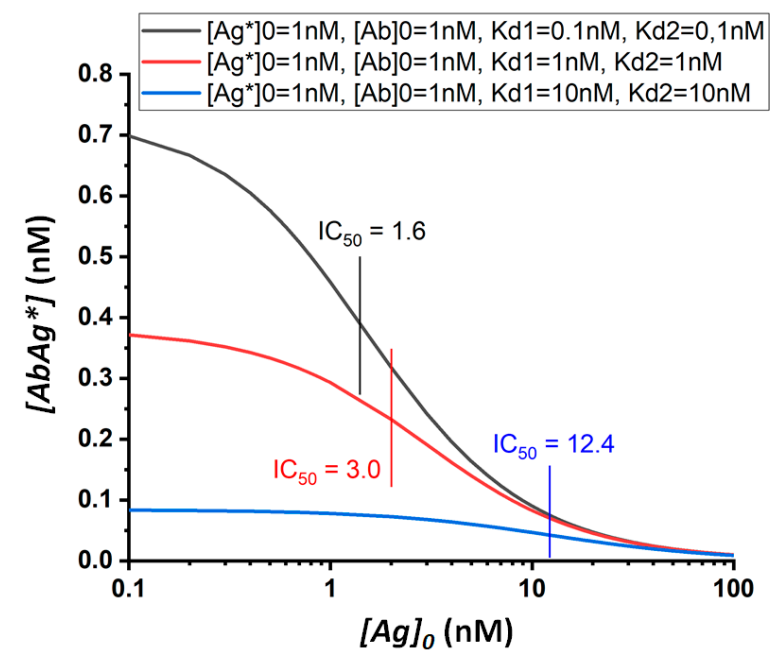

(a)

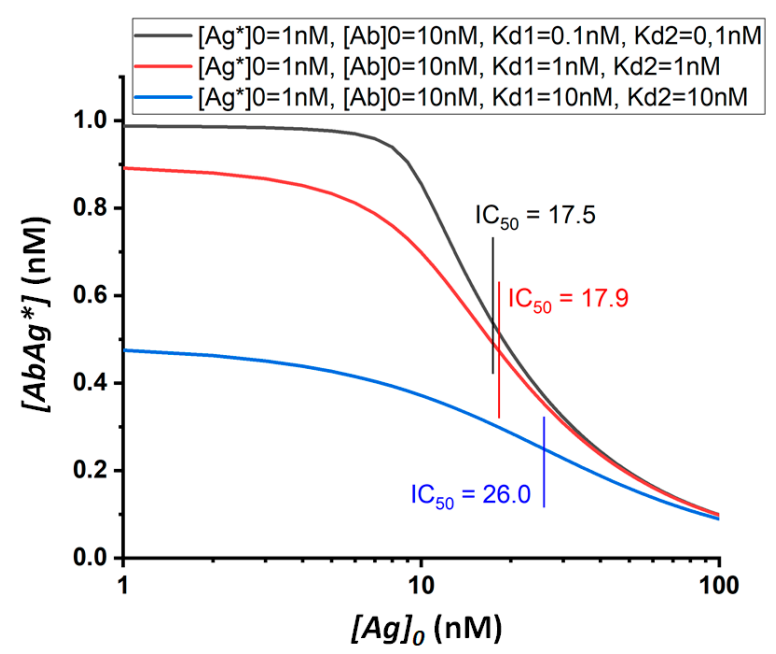

(b)

Figure 3. Cont. 


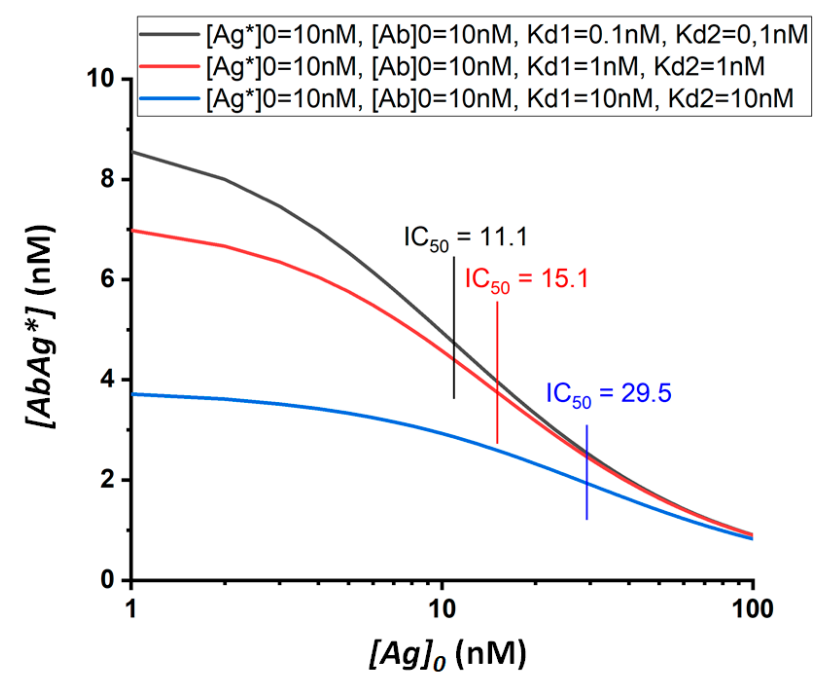

(c)

Figure 3. Theoretical calibration dependences of equilibrium competitive immunoassay for three model structurally similar compounds (I, II, and III; black, red, and blue curves in each sub-figure, respectively) and three assay formats differing in the used concentrations of analytical reactants: (a) $[A b]_{0}=1 \mathrm{nM},\left[A g^{*}\right]_{0}=1 \mathrm{nM}$; (b) $[A b]_{0}=10 \mathrm{nM},\left[A g^{*}\right]_{0}=1 \mathrm{nM}$; (c) $[A b]_{0}=10 \mathrm{nM},\left[A g^{*}\right]_{0}=10 \mathrm{nM}$.

The $\mathrm{IC}_{50}$ values calculated using these curves are integrated in Table 1. Cross-reactivity can be quantified in terms of the ratio of the $\mathrm{IC}_{50}$ values for compounds I, II, and III. The presented data confirm the change in $\mathrm{IC}_{50}$ with varying concentrations of analytical reactants. Thereby, cross-reactivity is not an intrinsic fixed characteristic of either the antibody itself or its combination with a competitor used in the analysis, but rather reflects the properties of a particular assay and its conditions. Therefore, the same antigen-antibody pair used in different methods of analysis will give different spectra of cross-reactivity values for structurally similar compounds.

Table 1. $\mathrm{IC}_{50}$ values $(\mathrm{nM})$ for the calibration dependences given in Figure 3.

\begin{tabular}{ccccccc}
\hline \multirow{2}{*}{$\begin{array}{c}\text { Analytes with } \\
\text { Different Affinities }\end{array}$} & \multicolumn{2}{c}{ Assay (a) } & \multicolumn{2}{c}{ Assay (b) } & \multicolumn{2}{c}{ Assay (c) } \\
\cline { 2 - 7 } & $\mathbf{I C}_{\mathbf{5 0}, \mathbf{n M}}$ & $\mathbf{C R}, \mathbf{\%}$ & $\mathrm{IC}_{\mathbf{5 0}}, \mathbf{n M}$ & $\mathbf{C R}, \mathbf{0}$ & $\mathbf{I C}_{\mathbf{5 0}, \mathbf{n M}}$ & $\mathbf{C R}, \mathbf{0}$ \\
\hline $\begin{array}{c}\text { Analyte I } \\
\left(\mathrm{K}_{\mathrm{d}}=0.1 \mathrm{nM}\right)\end{array}$ & 1.6 & 100 & 17.5 & 100 & 11.1 & 100 \\
$\begin{array}{c}\text { Analyte II } \\
\left(\mathrm{K}_{\mathrm{d}}=1 \mathrm{nM}\right)\end{array}$ & 3.0 & 53 & 17.9 & 98 & 15.1 & 74 \\
$\begin{array}{c}\text { Analyte III } \\
\left(\mathrm{K}_{\mathrm{d}}=10 \mathrm{nM}\right)\end{array}$ & 12.4 & 13 & 26.0 & 67 & 29.5 & 38 \\
\hline
\end{tabular}

The data obtained show that cross-reactivity depends both on the absolute value of the concentrations of the reactants and on their ratio.

In the case of equal concentrations of antibodies and labeled/immobilized antigens, the higher their concentration is, the higher the cross-reactivity will be. Thus, for $[A b]_{0}=$ $\left[A g^{*}\right]_{0}=1 \mathrm{nM}$, the $\mathrm{IC}_{50}$ values for antigens with $\mathrm{K}_{\mathrm{d}}=0.1$ and $10 \mathrm{nM}$ differ by a factor of almost eight (Figure 3a, Table 1 ), while with $[A b]_{0}$ and $\left[A g^{*}\right]_{0}$ being 10 times higher, the $\mathrm{IC}_{50}$ values for the same antigens will differ by a factor of 2.7 (Figure 3c, Table 1). The ratio of reagents affects the cross-reactivity even more strongly. For example, at concentrations of $\left[A g^{*}\right]_{0}$ and $[A b]_{0}$ equal to 1 and $10 \mathrm{nM}$, respectively, the $\mathrm{IC}_{50}$ values for antigens with $\mathrm{K}_{\mathrm{d}}$ 0.1 and $10 \mathrm{nM}$ differ by only 1.5 times (Figure $3 \mathrm{~b}$, Table 1 ). Thus, an approximately fivefold variation in CR values can be achieved (as follows from the comparison of Figure 3a, Table 1 and Figure 3b, Table 1). 
The most selective analysis can be obtained using approximately equal concentrations of antibodies and labeled/immobilized antigens. In this case, the lowest possible concentration of reagents should be used. The absolute values of the used concentrations are determined by minimal detectable concentrations of labels and will be lower for a more sensitive analysis.

The model considers the antibody preparation as a pool of molecules with the same properties, i.e., reflecting the situation for monoclonal antibodies. However, when considering an immunoassay in equilibrium mode, the separation of polyclonal antibodies into several groups with different affinities will give similar effects for each of these groups and for their combination. Therefore, predictions for monoclonal antibodies remain valid. The transition to kinetic immunoassays significantly increases the number of variants and opens up opportunities for more complex effects.

\subsection{Experimental Validation of the Model}

For experimental confirmation of the established theoretical dependences, immunochemical determination of a group of structurally similar compounds from the sulfonamide class was carried out. Seven compounds were tested in two variants of the equilibrium competitive immunoassay: ELISA and FPIA. It should be noted that the competing antigen preparations, namely an SA-protein conjugate for ELISA and an SA-(fluorescein derivative) conjugate for FPIA, were synthesized using the same modification of SA coinciding with the kind of activation and orientation in the conjugates. Therefore, the demonstrated properties of the two assays are not associated with different immune recognition of SA derivatives.

For both immunoassay variants, preliminary optimization of conditions was carried out, providing the highest detection sensitivity of target analytes and acceptable signal amplitude. In the final variants of the analyses, the following ratios of reagents were selected: for ELISA, the concentration of the hapten-protein immobilized on the plate was $76 \mathrm{nM}$ and the concentration of specific antibodies was $0.3 \mathrm{nM}$; for FPIA, the concentration of SA-(fluorescein derivative) conjugate was $0.16 \mathrm{nM}$ and the concentration of specific antibodies was $0.2 \mathrm{nM}$. It should be noted that for both assays, the time of immune interaction ( $5 \mathrm{~min}$ for homogeneous FPIA and $1 \mathrm{~h}$ for heterogeneous ELISA) provided the possibility to reach chemical equilibrium, and its increase for both cases did not lead to significant changes in the registered signal and analytical parameters (limit of detection, working range).

The chosen concentrations of antibodies were comparable for both assays, while the concentrations of the modified haptens differed by orders of magnitude and were significantly higher for ELISA compared to FPIA. Note that the true concentrations of the active hapten bound to the surface of the microplate are unknown. The concentration of the hapten-protein conjugate used for immobilization was 475 times higher than the concentration of the SA-(fluorescein derivative) conjugate in FPIA. Even taking into account the fact that, according to existing concepts, when immobilized on a plate, more than $90 \%$ of the protein may lose activity [56-58], it can be argued that the concentration of the modified hapten ( $\mathrm{Ag}^{*}$ in the proposed model) is several times higher for ELISA than for FPIA. This means that the ELISA is predicted to be more cross-reactive than FPIA is.

The results obtained for the determination of SAs by two methods and integrated in Table 2 confirmed the prediction of the model: the cross-reactivity of ELISA exceeded the cross-reactivity of FPIA by up to 8.5 times (for sulfadimethoxine). Thus, it was confirmed that the cross-reactivity of the immunoassay depends not only on the properties of the antibodies used, but also on the specific parameters of the analysis technique, such as the ratio of the concentrations of the antibodies and modified hapten that are used to realize the given assay format. 
Table 2. Sulfonamides used in the work and their $\mathrm{IC}_{50}$ and $\mathrm{CR}$ values relative to sulfachlorpyridazine for FPIA and ELISA techniques.

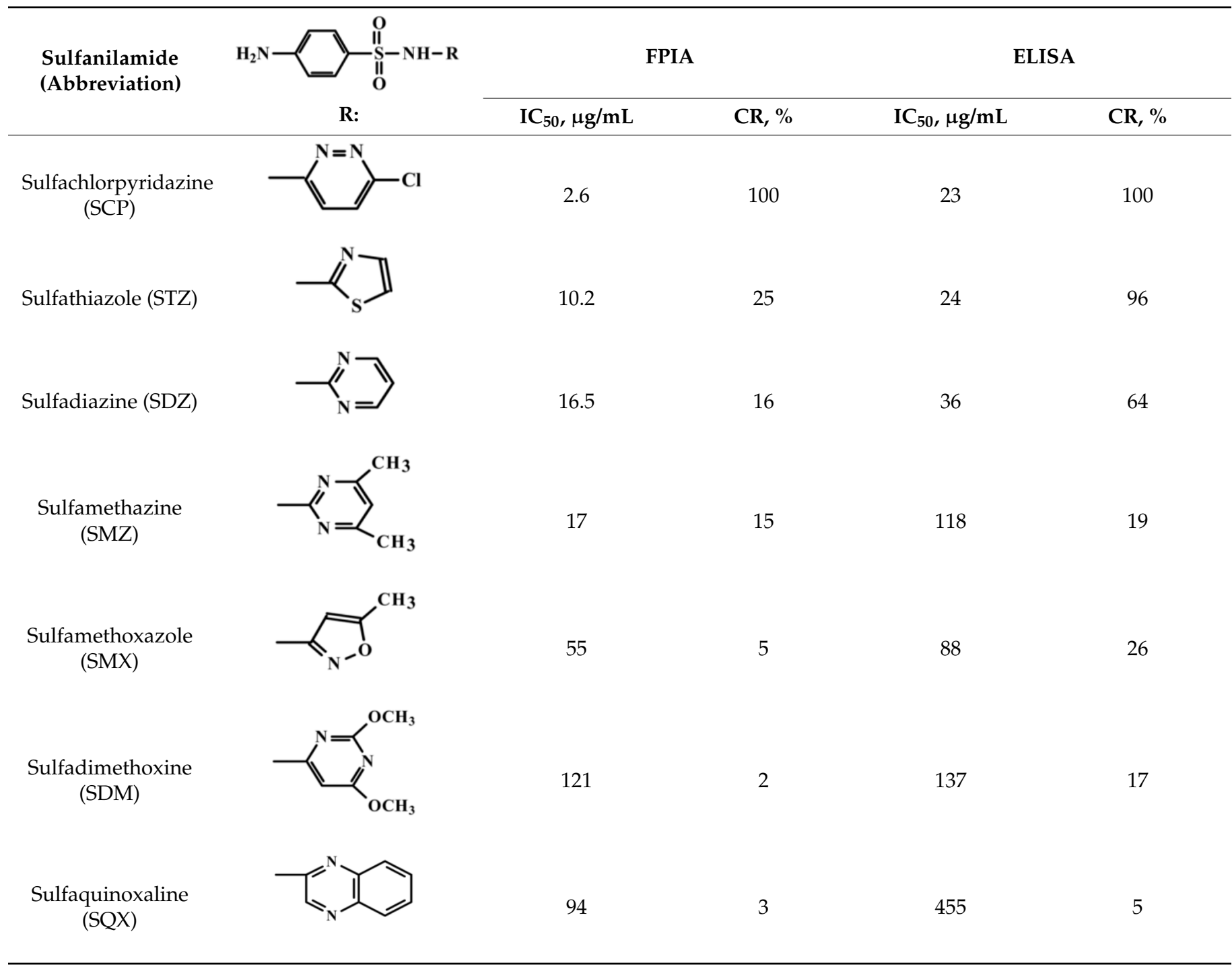

The cross-reactivity can also be modulated by varying the concentrations and ratios of the reagents in the same assay format. We have shown this possibility considering the crossreactivities for four sulfonamides, presented in Table 3, in the course of their determination using the FPIA technique. With an increase in the concentrations of antibodies and labeled hapten derivative by five times, the cross-reactivity increased from 2 (for sulfadiazine) to 9.5 times (for sulfadimethoxine).

Table 3. Determination of $\mathrm{IC}_{50}$ values of FPIA calibration curves and cross-reactivity of sulfonamides at various concentrations of antibodies and labeled hapten. A-the concentration of SA-(fluorescein derivative) conjugate $=0.16 \mathrm{nM}$, the concentration of specific antibodies $=0.2 \mathrm{nM}$. B-the concentration of SA-(fluorescein derivative) conjugate $=0.8 \mathrm{nM}$, the concentration of specific antibodies $=1 \mathrm{nM}$.

\begin{tabular}{|c|c|c|c|c|}
\hline Sulfanilamide & $\begin{array}{c}\mathrm{IC}_{50}, \mu \mathrm{g} / \mathrm{mL} \\
\mathrm{A}\end{array}$ & $\begin{array}{c}\mathrm{CR}, \% \\
\mathrm{~A}\end{array}$ & $\begin{array}{c}\mathrm{IC}_{50}, \mu \mathrm{g} / \mathrm{mL} \\
\mathrm{B}\end{array}$ & $\begin{array}{c}\text { CR, \% } \\
\text { B }\end{array}$ \\
\hline Sulfachlorpyridazine & 2.6 & 100 & 23 & 100 \\
\hline Sulfadiazine & 16.5 & 16 & 75 & 31 \\
\hline Sulfamethazine & 17 & 15 & 50 & 46 \\
\hline Sulfadimethoxine & 121 & 2 & 120 & 19 \\
\hline
\end{tabular}




\subsection{Experimental Validation of the Model}

For non-equilibrium conditions, the cross-reactivity can also depend on the duration of the immune interaction. For the homogeneous analysis (FPIA), an equilibrium was reached faster, but the time of reagents' incubation in the heterogeneous ELISA was almost an order of magnitude longer $(1 \mathrm{~h})$ than in FPIA (10 min). At a kinetic association constant of $10^{6} 1 /(\mathrm{M} * \mathrm{~s})$ and reagent concentrations of $1 \mathrm{nM}$, the reaction approached an equilibrium by $95 \%$ in $1 \mathrm{~h}$ and the analysis could be considered as an equilibrium one, but at lower association constants, the analysis under a common ELISA duration $(1 \mathrm{~h})$ will be a non-equilibrium one.

To study the effect of kinetic parameters on the specificity of the analysis, a model based on the approximation of equilibrium conditions is not suitable. Therefore, we used a numerical approach to solve the kinetic equations of the reactions, implementing the COPASI software for this purpose. The parameters taken for calculations are described in the Supplementary Materials section. The obtained theoretical calibration curves (Figure S1) demonstrate that as an equilibrium is approached, the differences in the detection sensitivity of analytes with different binding constants increase. As can be seen from Table 4, at a reaction time of $600 \mathrm{~s}$, the $\mathrm{IC}_{50}$ values for analytes with kinetic association constants of $10^{6}$ and $10^{7} \mathrm{M}^{-1} \mathrm{~s}^{-1}$ differ by a factor of 1.5 , while at a reaction time of $3600 \mathrm{~s}$, the $\mathrm{IC}_{50}$ values for the same analytes differ by a factor of 6.4. Thus, for non-equilibrium assays, the cross-reactivity also depends on the assay duration. To obtain broad specificity, the competitive stage of the assay should be shortened.

Table 4. $\mathrm{IC}_{50}$ values of theoretical calibration curves of non-equilibrium competitive assay for varied durations of immune interaction $(t)$ and varied kinetic association constants $(k a)$. The concentration of antigen derivative $\left[\mathrm{Ag}^{*}\right]_{0}$ was $0.16 \mathrm{nM}$, the concentration of specific antibodies $[A b]_{0}$ was $0.2 \mathrm{nM}$, all kinetic dissociation constants $\mathrm{k}_{\mathrm{d}}$ were $0.00011 / \mathrm{s}$, and the association constant with modified antigen $\mathrm{k}_{\mathrm{a} 2}$ was $10^{7} \mathrm{M}^{-1} \mathrm{~s}^{-1}$.

\begin{tabular}{ccc}
\hline \multirow{2}{*}{$\boldsymbol{t} \mathbf{s}$} & \multicolumn{2}{c}{$\mathbf{I C}_{\mathbf{5 0}, \mathbf{n M}}$} \\
\cline { 2 - 3 } & $\mathbf{k}_{\mathbf{a}}=\mathbf{1 0}^{\mathbf{6}} \mathbf{M}^{\mathbf{- 1}} \mathbf{s}^{-\mathbf{1}}$ & $\mathbf{k}_{\mathbf{a}}=\mathbf{1 0}^{\mathbf{7}} \mathbf{M}^{-\mathbf{1}} \mathbf{s}^{\mathbf{- 1}}$ \\
\hline 600 & 4.46 & 2.94 \\
3600 & 2.61 & 0.41 \\
\hline
\end{tabular}

To verify the above given theoretical assumptions, an enzyme-linked immunosorbent assay was implemented for three antibiotics from the class of fluoroquinolones: clinafloxacin, moxifloxacin, and enrofloxacin. The determined parameters of the assay specificity at different durations of immune interaction are summarized in Table 5. As expected, the differences in $\mathrm{IC}_{50}$ values and, accordingly, in cross-reactivities were several times greater for the assay with an hour-long incubation of the analyte with antibodies than for the assay with incubation for $7 \mathrm{~min}$. The $\mathrm{CR}$ values for clinafloxacin and enrofloxacin differed by 4.6 times with 7-minute incubation and by 50 times with an hour of incubation (the ratio was increased by 11 times).

Table 5. $\mathrm{IC}_{50}$ values of experimental calibration curves and cross-reactivities for the competitive assay of fluoroquinolones at varied durations of immune interaction.

\begin{tabular}{ccccc}
\hline & \multicolumn{5}{c}{ Duration of Immune Interaction, min } \\
\cline { 2 - 5 } Analyte & $\mathbf{7}$ & $\mathbf{6 0}$ & $\mathbf{7}$ & $\mathbf{6 0}$ \\
\cline { 2 - 5 } & \multicolumn{2}{c}{$\mathbf{I C}_{\mathbf{5 0}}, \mathbf{n g} / \mathbf{m L}$} & $\mathbf{C R}, \mathbf{\%}$ \\
\hline Clinafloxacin & 30 & 9 & 100 & 100 \\
Moxifloxacin & 33 & 23 & 91 & 39 \\
Enrofloxacin & 137 & 430 & 22 & 2 \\
\hline
\end{tabular}




\subsection{Potential Applicability of the Presented Results to Biosensors}

The results obtained indicate that the cross-reactivity of an analysis based on immune or other bioreceptor recognition can be changed without the need for new immunoreagents/bioreceptors. Efficient ways of changing the reactivity include the following:

(1) Changing the label to one to be detected at higher or lower concentrations;

(2) Changing the ratio of the concentrations for the receptor molecules and the modified competing derivative of the analyte to be determined ( $[A b]_{0}$ and $\left[\mathrm{Ag}^{*}\right]_{0}$ in the model considered above).

Both of these can be implemented in competitive biosensor systems. Competitive schemes of assays, along with direct schemes of assays [59], are widely used to determine low molecular weight analytes, including practically important groups of compounds such as hormones, antibiotics, pesticides, etc. Competitive biosensors provide the possibility of generating a signal from an electrochemically active, optically active, or other label that is included into the analyte-receptor complex on the sensory surface. Enzymes, nanoparticles, and other structures can be such labels in biosensors [60,61]. Optical, electrochemical, thermometric, piezoelectric, or magnetic signals generated by the labels reflect the result of competition for binding with the receptor molecule of the modified analyte and the analyte in the tested sample. The given competition makes it possible to calculate the analyte content in the samples based on the signal of the biosensor.

Depending on the similarity or difference in the biological effects of structurally related compounds, a practical need may consist in either (i) a decrease in binding to the receptor during the analysis of all compounds, except for the main one determined, or (ii) the maximum degree of binding for structurally related compounds (see works [11-44], considered in Section 1 as examples of solving such common problems). The results of our study show that significant progress towards this goal can be achieved using the bioanalytical reagents already available to the researcher, without labor-intensive or expensive production or purchase of new reagents.

In general, the necessary actions can be incorporated into the following methodologies.

(1) If it is necessary for the immunosensor to be narrowly selective, i.e., to reduce the $\mathrm{CR}$ for structural analogs of the only target analyte, it is necessary to reduce the concentrations of antibodies and modified competing antigens and to alter their molar ratio to 1:1. In order for such a decrease to not interfere with accurate registration of the biosensor signal, a label should be included in the immune complexes that can be detected at lower concentrations, such as an enzyme with a higher specific activity, a more intensely absorbing or fluorescent optical label, or an effective amplifier of an electrical signal. A possible variant of such an enhanced label consists in the formation of oligomeric complexes from several initial labels by their chemical conjugation or affine aggregation during the work of the sensor. (See recent reviews [62-65] with descriptions of such amplifying techniques.)

(2) If it is necessary to expand the selectivity of the immunosensor, i.e., to increase the CR for structurally similar compounds recognized by the used antibodies, the opposite actions are required - an increase in the concentrations of antibodies and modified competing antigens and their use in a non-equimolar ratio. Immunosensor analysis under such conditions could be realized by using the same signal measurement protocol or with a simple reduction in the duration of the signal generation. If the increasing signal causes any complications in accurate quantitative registration, it is justified to replace the label with another one that is detected at higher concentrations. In this case, the possibility should be taken into account that actions to increase the $\mathrm{CR}$ will cause some deterioration in the sensitivity of the immunosensor (an increase in the minimum detectable concentration). However, many existing biosensors detect analytes in lower concentrations that have a margin of sensitivity that is similar to the maximum permissible level of contaminants, so the modified biosensors may retain their practical functionality. 
The methodologies given above were formulated for immunosensors only to simplify the terminology and to provide its compliance with the theoretical and experimental results discussed above. The same methodologies are recommended for biosensors with other receptor molecules (aptamers, lectins, etc.).

\section{Conclusions}

To date, a number of approaches to modulate the cross-reactivity of immunoanalytical systems have been described. However, additional solutions not related to the specific features of individual analytes are still in demand. The results obtained in the presented study demonstrate the capabilities of simple approaches to managing the selectivity of immunodetection, which do not require additional reagents, sample modification, and other complex preliminary development actions. In situations where structurally similar compounds with different affinities are potentially present in the samples to be tested, conclusions about the excess permissible concentration of toxic contaminants based on the integral immunoanalytical signal (total quantity of formed immune complexes) are associated with significant risks of false positive and false negative results, depending on the ratio of different compounds detected. The transition from one analysis format to another makes it possible either to minimize the undesirable contribution of less affine and non-hazardous compounds (lowering cross-reactivity), or to bring the detected total signal closer to the real sum of concentrations of the analytes (increasing cross-reactivity). At the same time, the problem of switching to other concentrations of reagents can be solved by simply replacing one marker with another, taking into account the variety of works in recent years on the characterization of alternative markers for different formats of immunoassay. An alternative way based on changes in immunoreactants' concentrations and/or shifting from the kinetic or equilibrium mode of the assay could be implemented without any changes to the reactants used. Of course, the capabilities of real systems are determined by a combination of many factors, the effects of which make it possible to modulate crossreactivity. However, the proposed approach expands this toolkit, characterized by its ease of application for different analytes. Without giving up the opportunity of having a more radical influence on specificity by changing the structure of the antigen-binding site of antibodies, the proposed approach could be considered to meet a variety of demands in applications such as medical and veterinary diagnostics, control of food and feed, protection of public safety, and monitoring of natural resources.

Supplementary Materials: The following are available online at https:/ / www.mdpi.com/article/10 .3390/app11146581/s1, Numerical modeling of competitive immunochromatographic analysis.

Author Contributions: Conceptualization, D.V.S., A.V.Z. and B.B.D.; investigation, D.V.S. and E.A.Z.; methodology, D.V.S., A.V.Z. and B.B.D.; resources, D.V.S. and S.A.E.; validation, D.V.S.; visualization, D.V.S. and A.V.Z.; writing-original draft preparation, D.V.S. and A.V.Z.; writing-review and editing, D.V.S., A.V.Z. and B.B.D. All authors have read and agreed to the published version of the manuscript.

Funding: This research was funded by the Russian Science Foundation, grant number 20-76-10033.

Data Availability Statement: Data are contained within the article. Data of modeling, calculations, and verifications are available on request from the corresponding author.

Conflicts of Interest: The authors declare no conflict of interest.

\section{References}

1. Li, Y.F.; Sun, Y.M.; Beier, R.C.; Lei, H.T.; Gee, S.; Hammock, B.D.; Wang, H.; Wang, Z.H.; Sun, X.L.; Shen, Y.D.; et al. Immunochemical techniques for multianalyte analysis of chemical residues in food and the environment: A review. TRAC Trends Anal. Chem. 2017, 88, 25-40. [CrossRef]

2. Ross, G.M.S.; Bremer, M.G.E.G.; Nielen, M.W.F. Consumer-friendly food allergen detection: Moving towards smartphone-based immunoassays. Anal. Bioanal. Chem. 2018, 410, 5353-5371. [CrossRef] [PubMed]

3. Ravi, N.; Cortade, D.L.; Ng, E.; Wang, S.X. Diagnostics for SARS-CoV-2 detection: A comprehensive review of the FDA-EUA COVID-19 testing landscape. Biosens. Bioelectr. 2020, 165, 112454. [CrossRef] 
4. Starodub, N.F.; Melnychuk, M.D. Efficiency of biosensors as new generation of analytical approaches at the biochemical diagnostics of diseases. In Advanced Biomaterials and Biodevices; Tiwari, A., Nordin, A.N., Eds.; Scrivener Publishing: Beverly, CA, USA, 2014; pp. 451-485.

5. Yang, J.C.; Wang, K.; Xu, H.; Yan, W.Q.; Jin, Q.H.; Cui, D.X. Detection platforms for point-of-care testing based on colorimetric, luminescent and magnetic assays: A review. Talanta 2019, 202, 96-110. [CrossRef]

6. Zhu, G.Y.; Yin, X.D.; Jin, D.L.; Zhang, B.; Gu, Y.Y.; An, Y.R. Paper-based immunosensors: Current trends in the types and applied detection techniques. TRAC Trends Anal. Chem. 2019, 111, 100-117. [CrossRef]

7. Cavalera, S.; Di Nardo, F.; Forte, L.; Marinoni, F.; Chiarello, M.; Baggiani, C.; Anfossi, L. Switching from multiplex to multimodal colorimetric lateral flow immunosensor. Sensors 2020, 20, 6609. [CrossRef] [PubMed]

8. Wild, D. The Immunoassay Handbook. Theory and Applications of Ligand Binding, ELISA and Related Techniques, 4th ed.; Elsevier Science: Amsterdam, The Netherlands, 2013; pp. 15-242.

9. Dzantiev, B.B.; Urusov, A.E.; Zherdev, A.V. Modern techniques of immunochemical analysis: Integration of sensitivity and rapidity. In Biochemistry and Biotechnology for Modern Medicine; Komisarenko, S., Ed.; Publishing House Moskalenko O.M.: Kyiv, Ukraine, 2013; pp. 382-399.

10. Murphy, C.; Gilgunn, S.; O'Kennedy, R. An overview of immunoassays. In Immunoassays: Development, Applications and Future Trends; O'Kennedy, R., Murphy, C., Eds.; Pan Stanford Publishing Pte Ltd.: Singapore, 2017; pp. 1-86.

11. Selby, C. Interference in immunoassay. Ann. Clin. Biochem. 1999, 36, 704-721. [CrossRef] [PubMed]

12. Miller, J.J.; Levinson, S.S. Interferences in Immunoassay. In Immunoassay; Diamandis, E.D., Christopoulos, T.K., Eds.; Academic Press: San Diego, CA, USA, 1996; Chapter 7; pp. 165-190.

13. Glass, T.R.; Ohmura, N.; Morita, K.; Sasaki, K.; Saiki, H.; Takagi, Y.; Kataoka, C.; Ando, A. Improving an immunoassay response to related polychlorinated biphenyl analytes by mixing antibodies. Anal. Chem. 2016, 78, 7240-7247. [CrossRef] [PubMed]

14. Strasser, A.; Usleber, E.; Schneider, E.; Dietrich, R.; Burk, C.; Martlbauer, E. Improved enzyme immunoassay for group-specific determination of penicillins in milk. Food Agric. Immunol. 2003, 15, 135-143. [CrossRef]

15. Pastor-Navarro, N.; Gallego-Iglesias, E.; Maquieira, A.; Puchades, R. Development of a group-specific immunoassay for sulfonamides-Application to bee honey analysis. Talanta 2007, 71, 923-933. [CrossRef]

16. Yuan, Y.; Zhao, Y.Y.; Wu, K.; Yang, H.; Zhao, K.; Li, J.G.; Deng, A.P. A sensitive and group-specific monoclonal antibody-based indirect competitive ELISA for the determination of salbutamol in swine meat and liver samples. Anal. Methods 2017, 9, 5806-5815. [CrossRef]

17. Chae, W.; Kim, P.; Kim, H.; Cheong, Y.C.; Kim, Y.S.; Kang, S.M.; Seong, B.L. Hemagglutinin quantitative ELISA-based potency assay for trivalent seasonal influenza vaccine using group-specific universal monoclonal antibodies. Sci. Rep. 2019, 9, 19675. [CrossRef] [PubMed]

18. Zhang, Q.; Zhang, W.; Wang, X.P.; Li, P.W. Immunoassay development for the class-specific assay for types I and II pyrethroid insecticides in water samples. Molecules 2010, 15, 164-177. [CrossRef]

19. Lee, N.; McAdam, D.P.; Skerritt, J.H. Development of immunoassays for type II synthetic pyrethroids. 1. Hapten design and application to heterologous and homologous assays. J. Agric. Food Chem. 1998, 46, 520-534. [CrossRef] [PubMed]

20. Nara, S.; Tripathi, V.; Chaube, S.K.; Rangari, K.; Singh, H.; Kariya, K.P.; Shrivastav, T.G. Use of biotin-streptavidin system for developing a viable, sensitive and specific antigen heterologous assay for hapten. Talanta 2008, 77, 210-216. [CrossRef] [PubMed]

21. Wang, C.M.; Li, X.B.; Liu, Y.H.; Guo, Y.R.; Xie, R.; Gui, W.J.; Zhu, G.N. Development of a Mab-based heterologous immunoassay for the broad-selective determination of organophosphorus pesticides. J. Agric. Food Chem. 2010, 58, 5658-5663. [CrossRef]

22. Wang, Z.H.; Zhang, H.Y.; Ni, H.J.; Zhang, S.X.; Shen, J.Z. Development of a highly sensitive and specific immunoassay for enrofloxacin based on heterologous coating haptens. Anal. Chim. Acta 2014, 820, 152-158. [CrossRef]

23. Wang, J.; Bever, C.R.S.; Majkova, Z.; Dechant, J.E.; Yang, J.; Gee, S.J.; Xu, T.; Hammock, B.D. Heterologous antigen selection of camelid heavy chain single domain antibodies against tetrabromobisphenol A. Anal. Chem. 2014, 86, 8296-8302. [CrossRef] [PubMed]

24. Burkin, M.A.; Galvidis, I.A.; Eremin, S.A. Specific and generic immunorecognition of glycopeptide antibiotics promoted by unique and multiple orientations of hapten. Biosens. Basel 2019, 9, 52. [CrossRef]

25. Ceballos-Alcantarilla, E.; López-Puertollano, D.; Agulló, C.; Abad-Fuentes, A.; Abad-Somovilla, A.; Mercader, J.V. Combined heterologies for monoclonal antibody-based immunoanalysis of fluxapyroxad. Analyst 2018, 143, 5718-5727. [CrossRef]

26. Wang, Z.H.; Li, Y.H.; Liang, X.; Zhang, S.X.; Shi, W.M.; Shen, J.Z. Forcing immunoassay for sulfonamides to higher sensitivity and broader detection spectrum by site heterologous hapten inducing affinity improvement. Anal. Methods 2013, 5, 6990-7000. [CrossRef]

27. Oubina, A.; Barcelo, D.; Marco, M.P. Effect of competitor design on immunoassay specificity: Development and evaluation of an enzyme-linked immunosorbent assay for 2,4-dinitrophenol. Anal. Chim. Acta 1999, 387, 267-279. [CrossRef]

28. Lu, N.; Ling, L.; Guan, T.; Wang, L.T.; Wang, D.; Zhou, J.H.; Ruan, T.; Shen, X.; Li, X.M.; Sun, Y.M.; et al. Broad-specificity ELISA with a heterogeneous strategy for sensitive detection of microcystins and nodularin. Toxicon 2020, 175, 44-48. [CrossRef]

29. Yuan, M.; Liu, B.; Liu, E.M.; Sheng, W.; Zhang, Y.; Crossan, A.; Kennedy, I.; Wang, S. Immunoassay for phenylurea herbicides: Application of molecular modeling and quantitative structure-activity relationship analysis on an antigen-antibody interaction study. Anal. Chem. 2011, 83, 4767-4774. [CrossRef] 
30. Wang, Z.H.; Kai, Z.P.; Beier, R.C.; Shen, J.Z.; Yang, X.L. Investigation of antigen-antibody interactions of sulfonamides with a monoclonal antibody in a fluorescence polarization immunoassay using 3D-QSAR models. Intern. J. Mol. Sci. 2012, 13, 6334-6351. [CrossRef] [PubMed]

31. Buglak, A.A.; Shanin, I.A.; Eremin, S.A.; Lei, H.T.; Li, X.M.; Zherdev, A.V.; Dzantiev, B.B. Ciprofloxacin and clinafloxacin antibodies for an immunoassay of quinolones: Quantitative structure-activity analysis of cross-reactivities. Intern. J. Mol. Sci. 2019, 20, 265. [CrossRef] [PubMed]

32. Wang, J.Y.; Peng, T.; Zhang, X.Y.; Xie, S.L.; Zheng, P.M.; Yao, K.; Ke, Y.B.; Wang, Z.H.; Jiang, H.Y. Application of quantitative structure-activity relationship analysis on an antibody and alternariol-like compounds interaction study. J. Mol. Recogn. 2019, 32, e2776. [CrossRef]

33. Waters, A.M.; Ozkan-Dagliyan, I.; Vaseva, A.V.; Fer, N.; Strathern, L.A.; Hobbs, G.A.; Tessier-Cloutier, B.; Gillette, W.K.; Bagni, R.; Whiteley, G.R.; et al. Evaluation of the selectivity and sensitivity of isoform- and mutation-specific RAS antibodies. Sci. Signal. 2017, 10. [CrossRef]

34. Piatesi, A.; Aldag, C.; Hilvert, D. Switching antibody specificity through minimal mutation. J. Mol. Biol. 2008, 377, 993-1001. [CrossRef] [PubMed]

35. Dzantiev, B.B.; Zherdev, A.V.; Romanenko, O.G.; Sapegova, L.A. Development and comparative study of different immunoenzyme techniques for pesticides detection. Intern. J. Environ. Anal. Chem. 1996, 65, 95-111. [CrossRef]

36. Huo, J.; Li, Z.; Wan, D.; Li, D.; Qi, M.; Barnych, B.; Vasylieva, N.; Zhang, J.; Hammock, B.D. Development of a highly sensitive direct competitive fluorescence enzyme immunoassay based on a nanobody-alkaline phosphatase fusion protein for detection of 3-phenoxybenzoic acid in urine. J. Agric. Food Chem. 2018, 66, 11284-11290. [CrossRef]

37. Lee, C.; Goeger, D.E. Interference of 6 beta-hydroxycortisol in the quantitation of urinary free cortisol by immunoassay and its elimination by solid phase extraction. Clin. Biochem. 1998, 31, 229-233. [CrossRef]

38. Sulea, T.; Rohani, N.; Baardsnes, J.; Corbeil, C.R.; Deprez, C.; Cepero-Donates, Y.; Robert, A.; Schrag, J.D.; Parat, M.; Duchesne, M.; et al. Structure-based engineering of $\mathrm{pH}$-dependent antibody binding for selective targeting of solid-tumor microenvironment. MABS 2020, 12. [CrossRef] [PubMed]

39. Oubiña, A.; Gascón, J.; Barceló, D. Determination of the cross-reactivities of immunoassays: Effect of common cross-reactants for chlorpyrifos-ethyl in water matrices using magnetic particle-based ELISA. Environ. Sci. Technol. 1996, 30, 513-516. [CrossRef]

40. Sasaki, K.; Oguma, S.; Glass, T.; Namiki, Y.; Sugiyama, H.; Ohmura, N.; Blake, D.A. Simple method to reduce interference from excess magnesium in cadmium immunoassays. J. Agric. Food Chem. 2008, 56, 7613-7616. [CrossRef] [PubMed]

41. Petrie, M.; Lynch, K.L.; Ekins, S.; Chang, J.S.; Goetz, R.J.; Wu, A.H.B.; Krasowski, M.D. Cross-reactivity studies and predictive modeling of "Bath Salts" and other amphetamine-type stimulants with amphetamine screening immunoassays. Clin. Toxicol. 2013, 51, 83-91. [CrossRef] [PubMed]

42. Kar, P.; Lipowsky, R.; Knecht, V. Importance of polar solvation for cross-reactivity of antibody and its variants with steroids. J. Phys. Chem. B 2011, 115, 7661-7669. [CrossRef]

43. Winger, L.A.; Dessi, J.L.; Self, C.H. Enhanced specificity for small molecules in a convenient format which removes a limitation of competitive immunoassay. J. Immunol. Methods 1996, 199, 185-191. [CrossRef]

44. Liu, X.B.; Eichenberger, M.; Fujioka, Y.; Dong, J.H.; Ueda, H. Improved detection sensitivity and selectivity attained by opensandwich selection of an anti-estradiol antibody. Anal. Sci. 2012, 28, 861-867. [CrossRef]

45. Tate, J.; Ward, G. Interferences in immunoassay. Clin. Biochem. Rev. 2004, 25, 105-120.

46. Marega, R.; Desroche, N.; Huet, A.C.; Paulus, M.; Pantaleon, C.S.; Larose, D.; Arbault, P.; Delahaut, P.; Gillard, N. A general strategy to control antibody specificity against targets showing molecular and biological similarity: Salmonella case study. Sci. Rep. 2020, 10, 1-14. [CrossRef]

47. Vojdani, A. Cross-reactivity of Aspergillus, Penicillium, and Stachybotrys antigens using affinity-purified antibodies and immunoassay. Arch. Environ. Health 2004, 59, 256-265. [CrossRef] [PubMed]

48. Wang, Z.X. An exact mathematical expression for describing competitive binding of two different ligands to a protein molecule. FEBS Lett. 1995, 360, 111-114. [CrossRef]

49. Sotnikov, D.V.; Zherdev, A.V.; Dzantiev, B.B. Mathematical modeling of bioassays. Biochemistry 2017, 82, 1744-1766. [CrossRef]

50. Roehrl, M.H.; Wang, J.Y.; Wagner, G. A general framework for development and data analysis of competitive high-throughput screens for small-molecule inhibitors of protein- protein interactions by fluorescence polarization. Biochemistry 2004, 43, 16056-16066. [CrossRef] [PubMed]

51. Holmes, T.H. Generalized mathematical model for immunoassay interference. Autoimmun. Rev. 2020, 19, 102663. [CrossRef]

52. Bitas, D.; Kabir, A.; Locatelli, M.; Samanidou, V. Food sample preparation for the determination of sulfonamides by highperformance liquid chromatography: State-of-the-art. Separations 2018, 5, 31. [CrossRef]

53. Chen, Y.; Liu, L.; Xu, L.; Song, S.; Kuang, H.; Cui, G.; Xu, C. Gold immunochromatographic sensor for the rapid detection of twenty-six sulfonamides in foods. Nano Res. 2017, 10, 2833-2844. [CrossRef]

54. Eremin, S.A.; Murtazina, N.R.; Ermolenko, D.N.; Zherdev, A.V.; Mart'ianov, A.A.; Yazynina, E.V.; Michura, I.V.; Formanovsky, A.A.; Dzantiev, B.B. Production of polyclonal antibodies and development of fluorescence polarization immunoassay for sulfanilamide. Anal. Lett. 2005, 38, 951-969. [CrossRef]

55. Ermolenko, D.N.; Eremin, S.A.; Mart'ianov, A.A.; Zherdev, A.V.; Dzantiev, B.B. A new generic enzyme immunoassay for sulfonamides. Anal. Lett. 2007, 40, 1047-1062. [CrossRef] 
56. Yakovleva, J.; Knopp, D.; Niessner, R.; Eremin, S.A. Development of a polarization fluoroimmunoassay for the herbicide metsulfuron-methyl. Food Agric. Immunol. 2002, 14, 217-229. [CrossRef]

57. Butler, J.E. Solid supports in enzyme-linked immunosorbent assay and other solid-phase immunoassays. Methods 2000, 22, 4-23. [CrossRef] [PubMed]

58. Dmitriev, A.D.; Tarakanova, J.N.; Yakovleva, D.A.; Dmitriev, D.A.; Phartooshnaya, O.V.; Kolyaskina, G.I.; Massino, Y.S.; Borisova, O.V.; Segal, O.L.; Smirnova, M.B.; et al. Monoclonal antibodies requiring coating buffer with low $\mathrm{pH}$ for efficient antigen capture in sandwich ELISA: The rarities or practically important phenomena? J. Immun. Immunochem. 2013, 34, 414-437. [CrossRef]

59. Yang, H.M.; Liang, S.J.; Tang, J.B.; Chen, Y.; Cheng, Y.Z. Immobilization of unraveled immunoglobulin G using well-oriented ZZ-His protein on functionalized microtiter plate for sensitive immunoassay. Anal. Biochem. 2013, 432, 134-138. [CrossRef] [PubMed]

60. Syazana, A.L.; Minhaz, U.A. Introduction to Immunosensors. In Immunosensors; Ahmed, M.U., Zourob, M., Tamiya, E., Eds.; Royal Chemical Society: Cambridge, UK, 2019; pp. 1-20.

61. Syahir, A.; Usui, K.; Tomizaki, K.; Kajikawa, K.; Mihara, H. Label and label-free detection techniques for protein microarrays. Microarrays 2015, 4, 228-244. [CrossRef]

62. Iglesias-Mayor, A.; Amor-Gutiérrez, O.; Costa-García, A.; de la Escosura-Muñiz, A. Nanoparticles as emerging labels in electrochemical immunosensors. Sensors 2019, 19, 5137. [CrossRef]

63. Bezinge, L.; Suea-Ngam, A.; de Mello, A.J.; Shih, C.-J. Nanomaterials for molecular signal amplification in electrochemical nucleic acid biosensing: Recent advances and future prospects for point-of-care diagnostics. Mol. Syst. Des. Eng. 2020, 5, 49-66. [CrossRef]

64. Cajigas, S.; Orozco, J. Nanobioconjugates for signal amplification in electrochemical biosensing. Molecules 2020, $25,3542$. [CrossRef]

65. Panferov, V.G.; Safenkova, I.V.; Zherdev, A.V.; Dzantiev, B.B. Methods for increasing sensitivity of immunochromatographic test systems with colorimetric detection (review). Appl. Biochem. Microbiol. 2021, 57, 143-151. [CrossRef] 